\title{
Managing Ischemic Heart Disease in Women: Role of a Women's Heart Center
}

\author{
Abha Khandelwal ${ }^{1} \cdot$ May Bakir $^{2} \cdot$ Meghan Bezaire $^{3} \cdot$ Briana Costello $^{4} \cdot$ Joanne Michelle D. Gomez $^{5} \cdot$ Valerie Hoover $^{6}$. \\ Noreen T. Nazir ${ }^{7} \cdot$ Katherine Nichols $^{8} \cdot$ Amy Reisenberg $^{9} \cdot$ Anupama Rao $^{10} \cdot$ Rupa Sanghani $^{3} \cdot$ Melissa Tracy $^{3}$. \\ Annabelle Santos Volgman 3,11 [
}

Accepted: 8 June 2021 / Published online: 4 August 2021

(c) The Author(s), under exclusive licence to Springer Science+Business Media, LLC, part of Springer Nature 2021

\begin{abstract}
Purpose of Review Heart centers for women (HCW) were developed due to the rising cardiovascular morbidity and mortality in women in the United States in the early 1990s. Our review encompasses the epidemiology, risk factors, diagnostic strategies, treatments, and the role of HCW in managing women with ischemic heart disease (IHD).

Recent Findings HCW use a multidisciplinary team to manage women with IHD. Due to the paucity of randomized controlled trials investigating various manifestations of IHD, some treatments are not evidence-based such as those for coronary microvascular dysfunction and spontaneous coronary artery dissection. Sex-specific risk factors have been identified and multimodality cardiac imaging is improving in diagnosing IHD in women. Treatments are being studied to help improve symptoms and outcomes in women with IHD.

Summary There has been progress in the care of women with IHD. HCW can be instrumental in treating women with IHD, doing research, and being a source of research study participants.
\end{abstract}

Keywords Myocardial infarction with non-obstructive coronary arteries (MINOCA) · Ischemia with non-obstructive coronary arteries (INOCA) · Multidisciplinary healthcare delivery $\cdot$ Sex differences in cardiovascular disease $\cdot$ Nonobstructive coronary artery disease

\section{Introduction}

Cardiovascular disease (CVD) remains the number one cause of mortality in women mostly due to ischemic heart disease (IHD) and stroke and appears to be increasing glob-

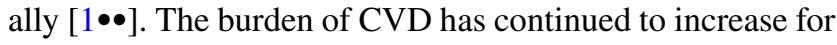
decades in almost all countries except for the high-income countries $[1 \bullet \bullet]$. Of great concern is trend of rising mortality from CVD in women and men in high-income countries such as the United States (US), where it was declining previously from 2000 to 2010 in women [2••]. This rising trend of CVD mortality in women was also seen in the 1990s when heart disease in women was less understood. In the $1980 \mathrm{~s}$ and 1990s, the prevention of IHD in women differed from

This article is part of the Topical Collection on Women and Ischemic Heart Disease

Annabelle Santos Volgman

Extended author information available on the last page of the article men due partly to the observational findings of the Nurses' Health Study (NHS) in 1985. The use of HRT was associated with a $50 \%$ reduction in the risk of coronary artery disease (CAD) outcomes in the 5-year follow-up NHS in 1985 [3]. In the same year, the Framingham Heart Study showed a $50 \%$ increased risk of cardiovascular morbidity and doubled the risk of cerebrovascular disease $[4 \bullet \bullet]$ in women using HRT compared to those who were not. Ultimately, NHS confirmed similar results in their 10-year follow-up study [5] and many postmenopausal women continued to be treated with HRT.

In the $1990 \mathrm{~s}$, cardiovascular mortality increased in women while decreasing in men [2••]. In the late 1990s and early 2000s, several randomized controlled trials (RCTs) revealed that HRT did not prevent CVD [6, 7]. The observational studies may have led to the increased CVD mortality seen in the 1990s and galvanized the need for better research and management of women with heart disease and led to the opening of heart centers for women $(\mathrm{HCW})[8 \bullet \bullet]$ and national healthcare organizations collaborated to improve 
cardiac care in women [9]. In 2004, sex-specific CVD guidelines emphasized the harm of HRT to prevent CVD and strongly encouraged the use of evidence-based therapies to lower CVD risk in women [10]. Guideline-derived medical therapy (GDMT), including diagnostic testing, lifestyle

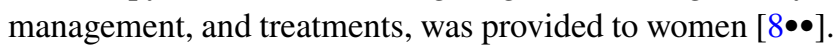
All these efforts are associated with the decline of CVD mortality in women from its peak in 2000 to its nadir in 2010 (Fig. 1).

Figure 1 shows the timeline of events that led to the current management of IHD in women. CVD mortality in both men and women is increasing since 2010, which is alarming and needs to be addressed. This review will summarize the management of IHD in women and the role of HCW in these patients' care.

\section{Epidemiology of CAD in Women}

CVD, comprised of CAD, heart failure (HF), stroke, and hypertension, is the leading cause of death of women in the US and globally. In American women, a prevalence of $48.4 \%$ resulted in 420,164 deaths in 2018, mostly due to CAD. The overall number of CVD deaths is slightly higher in men. However, sub-analysis by ethnicity shows that women account for a higher percentage of deaths in Blacks and His-

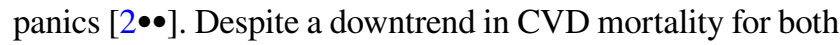
men and women in the US from 2000 to 2010, rates have been increasing since 2010 for both sexes, [11 ••] particu-

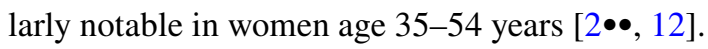

Women experience their first myocardial infarction (MI) roughly 10 years later than men, typically after menopause [13]. They are more likely to have longer door-to-balloon times, a lower rate of prescribed GDMT, and higher in-hos-

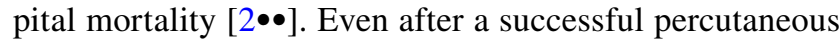
coronary intervention (PCI), women with acute coronary syndrome (ACS) have a 20\% higher adjusted mortality risk

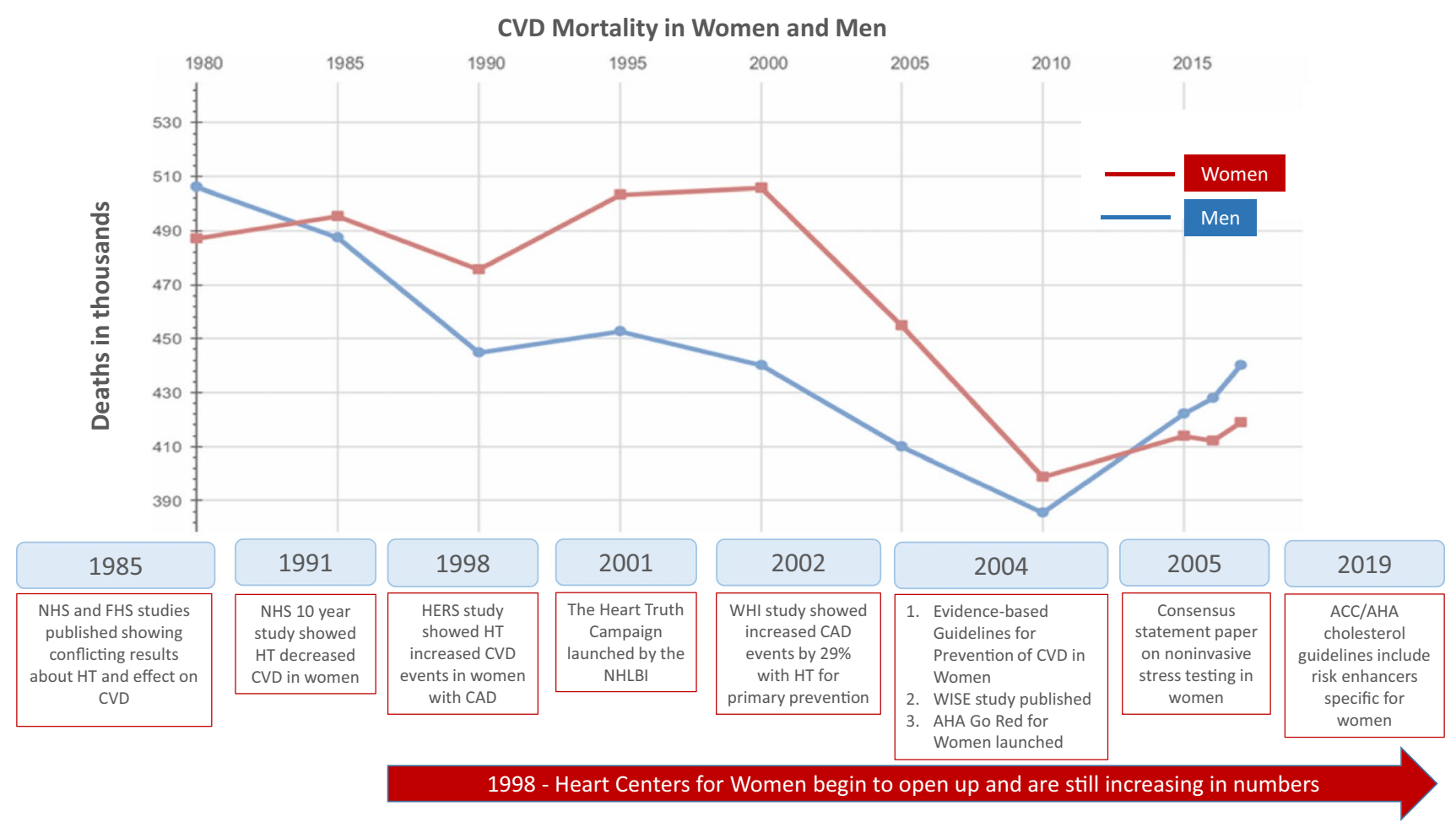

Fig. 1 Timeline of mortality in women and men from cardiovascular disease from 1980 to 2017. Timeline of observational (NHS, FHS, WISE) and randomized placebo-controlled studies (HERS and WHI) that led to guidelines and the management of ischemic heart disease in women. Also shown are the initiation of national campaigns to increase awareness of heart disease in women (NHLBI Heart Truth campaign and AHA Go Red for Women) and heart centers for women in the United States. Abbreviations: ACC, American
College of Cardiology; AHA, American Heart Association; CAD, coronary artery disease; CVD, cardiovascular disease; FHS, Framingham Heart Study; HERS, Heart and Estrogen/progestin Replacement Study; NHLBI, National Heart Lung and Blood Institute; NHS, Nurses' Health Study; WISE, Women's Ischemia Syndrome Evaluation. (Reprinted with permission Heart Disease and Stroke Statistics - Update 2021 (@2021 American Heart Association, Inc.) [4••] 
in the short term, and at 1 year for those over age 45 , a $74 \%$ survival rate vs. $81 \%$ in men [14•]. For those who survive an ACS, there is a higher risk of recurrent MI, HF, and death [15]. This risk is striking in women under 50 years old, where there is twice-higher mortality than men [16]. Overall, short- and long-term mortality with IHD is $40 \%$ higher in women after adjusting for age and comorbidities [12]. Given these statistics, all clinicians can significantly mitigate risk factors in women to decrease CAD development and IHD.

\section{Definition and Risk Factors for IHD}

IHD can be categorized as an acute or chronic condition. IHD can be due to obstructive and non-obstructive (defined as $<50 \%$ stenosis in epicardial coronary arteries) CAD. Traditional risk factors including hypertension, hyperlipidemia, diabetes, smoking, sedentary lifestyle, family history, chronic kidney disease, peripheral artery disease, and obesity are potentially modifiable contributors $[17 \bullet \bullet]$. More recent data investigating adverse pregnancy outcomes, systemic inflammatory disorders, obstructive sleep apnea, cancer-based therapy, and psychosocial contributors may disproportionately affect women [18•]. In implementing a $\mathrm{HCW}$, it is critical to have relationships with maternal fetal medicine, obstetrics, specialists in cardio-oncology, behavioral psychologists, and social work among many other disciplines to ensure adequate risk factor identification and treatment $[8 \bullet \bullet$. Barriers to heart care for women can be the unavailability of these services for patients at the medical facility.

Multiple reports indicate lower socioeconomic status (SES) in both sexes is associated with increased MI and death rates than those of higher SES, and it is a more powerful risk factor in women than in men [19•, 20•]. Those with an annual household income of $<\$ 20,000$ have a 4.91 -fold higher relative risk ratio of MI and cardiovascular death than those in higher-income brackets [21]. With $26.8 \%$ of femaleheaded households living below the US's poverty threshold, this subgroup is particularly susceptible [22]. Additionally, more social determinants of health (SDH) were associated with the increased age-adjusted incidence per 1000 personyears for fatal CHD [ $\geq 3$ SDH 2.86 vs. 0 SDH 1.3] and nonfatal MI [ $\geq 3$ SDH 5.44 vs. 3.91]. CV risk prediction calculators have begun to incorporate SES into their models [23].

Furthermore, research has demonstrated a dose effect between increasing SDHs and reduced odds of meeting clinical benchmarks for CVD risk factor control, i.e., blood pressure less than 140/90 mm Hg, A1C less than 7\%, physical activity of more than 150 min per week, and not smoking [24]. Additionally, emerging evidence suggests that depression and psychosocial stressors mediate associations between SDH and cardiovascular risk, underscoring the need for inclusion of clinical health psychology on interdisciplinary teams to comprehensively mitigate cardiac risk [25]. Cardiology providers should include an SDH assessment tool in their routine patient care; develop systems for routine collection, storage, and retrieval of SDH data; develop interprofessional practice models to address $\mathrm{SDH}$; and partner with community organizations to identify and support patients with SDH needs [26].

There is substantial evidence that poor mental health (e.g., depression, post-traumatic stress disorder, anxiety disorders, and other adverse psychological factors) is associated with worse cardiovascular health $[27 \bullet \bullet]$. The largest body of research examined the adverse bi-directional effects between depression and CAD. Depression occurs in up to one-third of patients with stable IHD, and the prevalence in women is about twice that of men [28, 29]. Depression is associated with increased risk for incident CAD, MI, and mortality following a cardiac event in both sexes and is an independent risk factor for poor prognosis in patients with ACS [27••]. Increasing evidence indicates that both direct (e.g., increased platelet aggregation, inflammation, and autonomic nervous system dysregulation) and indirect mechanisms (e.g., unhealthy lifestyle behaviors) contribute to these observed effects $[27 \bullet \bullet]$. HCW can address these psychosocial risks by collaborating with psychologists, psychiatrists, and social workers to facilitate urgent consultations and interventions. In a randomized, controlled trial of 237 consecutive women patients with CHD, a group-based cognitive behavioral therapy stress reduction program was associated with an almost threefold protective effect against all-cause mortality compared to usual care over the 9-year follow-up period (odds ratio, $0.33 ; 95 \% \mathrm{CI}, 0.15$ to $0.74 ; P=0.007$ ) [30].

Another randomized controlled trial included 362 women and men who experienced a CHD event in the previous 12 months and randomly assigned patients to a group-based cognitive behavioral therapy stress management program or usual care only. During the almost 8-month follow-up period, after controlling for potential confounders, patients in the intervention group had a $41 \%$ lower rate of fatal and non-fatal first recurrent CVD events (hazard ratio [95\% confidence interval], 0.59 [0.42-0.83]; $P=0.002$ ) with a strong, linear dose-response effect favoring better outcomes in those who attended more group sessions. Patients in the intervention group also experienced $45 \%$ fewer recurrent acute MIs (0.55 [0.36-0.85]; $P=0.007)$ [31]. Adverse pregnancy outcomes, including preterm labor, gestational diabetes, and hypertensive disorder of pregnancy, have been associated with increased risk of HF, CAD, and cardiovascular mor-

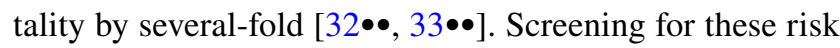
factors is critical as up to $20 \%$ of pregnancies can be affected 
[33••]. Cardio-obstetrics has become an essential part of $\mathrm{HCW}$ and requires close collaboration with obstetricians and maternal-fetal medicine specialists.

Systemic inflammatory disorders such as systemic lupus erythematosus and rheumatoid arthritis have a two- to threefold higher risk of MI and increased CVD mortality out of proportion to traditional risk factors. Further, joint involvement may limit regular exercise, and treatment may include corticosteroids which can lead to metabolic syndrome. Collaboration with rheumatologists to study commonality in microvascular disease to facilitate treatment for these diseases' cardiovascular manifestations is crucial [34•].

Radiation therapy can increase the rate of cardiac events by $7.4 \%$ per Gray of radiation. It is crucial to collaborate with cardio-oncology clinicians to survey and manage the cardiotoxicity of exposure to radiation, anthracyclines, monoclonal antibodies, and hormonal treatments [35].

Spontaneous coronary artery dissection (SCAD) is an increasingly recognized cause of IHD that disproportionately affects younger women and may be partly responsible for the increased mortality in 34-54-year-old women. The prevalence of typical risk factors is lower in these patients, and they account for $15-20 \%$ of acute MI during pregnancy. The risk factors for this condition are being investigated, and contributors include hormonal shifts, connective tissue disorders, fibromuscular dysplasia, myocardial bridge, and inciting triggers like intense Valsalva or stimulant use [36•].

\section{Evaluation of IHD in Women}

When evaluating women with IHD, a HCW program operates differently than some traditional prevention centers because it assesses for obstructive and non-obstructive causes for IHD.

\section{Coronary Artery Calcium Score}

Coronary artery calcium (CAC) is detected using rapid noncontrast ECG-gated CT scanning, and the CAC score can provide incremental information to refine CVD risk assessment using the Framingham risk score. The Multi-Ethnic Study of Atherosclerosis (MESA) examined the distribution of CAC in 6814 individuals with no known CAD or diabetes and followed for 10 years. The MESA calculator can reclassify individuals into the higher risk categories, identifying patients who can benefit from aggressive prevention strategies [37]. This strategy is critical in asymptomatic women who are at risk for MACE [38]. Data from the CAC consortium of 63,215 asymptomatic men and women showed similar long-term cardiovascular mortality in both men and women without CAC; however, women with CAC had a hazard ratio of 1.3 for cardiovascular mortality compared to men [39••]. These studies underscore the utility of CAC scoring in accurate CVD risk assessment and therapeutic guidance in women and is incorporated in the lipid guidelines using the pooled cohort equation [40••]. If the pooled cohort equation determination falls in the intermediate risk, the CAC score can be useful to help with the decision to treat a patient with statins without any substantial exposure to radiation [40••]. The typical radiation exposure with modern CT scanners is around $1 \mathrm{mSV}$, with newer reconstruction techniques and scanners being able to greatly minimize radiation exposure [41]. This degree of exposure is comparable to radiation from typical screening mammograms which are around $0.4 \mathrm{mSV}$ and chest X-ray $0.1 \mathrm{mSV}$ [42].

\section{Stress Testing}

Utilizing optimal stress tests for women is critical. Considerations in stress imaging are based on the pretest probability of IHD [43, 44•]. In women, further considerations include functional capacity, body habitus, imaging artifact, and radiation exposure to breast tissue [45]. Along with the typical presentation of angina, women may present with atypical angina symptoms [46]. Women tend to be older and have comorbidities when they become symptomatic and need evaluation for IHD, contributing to functional capacity limitations [45]. The electrocardiogram (EKG) component of exercise stress testing has a lower sensitivity and specificity for women compared to men and may lead to nondiagnostic EKG interpretation [47]. Over the last few years, there has been increasing focus on evaluating functional ischemia rather than just anatomic imaging for obstructive heart disease in women [48••].

Stress myocardial perfusion imaging (MPI) is recommended to diagnose IHD in women with intermediate to high risk who have resting EKG abnormalities [49]. MPI may be performed with single photon emission computed tomography (SPECT) or positron emission tomography (PET) imaging. SPECT is widely available and has robust data on its utility in women [49]. However, its limitations include false-positive studies from breast attenuation and obesity-related artifacts. Also, the lifetime risks related to ionizing radiation limits its use in younger women.

PET imaging has emerged over the last decade as a powerful tool in the assessment of functional ischemia, obviating the need for functional coronary angiography (FCA). It is particularly well suited for ischemic assessment in women since it has built-in attenuation correction and lowers radiation exposure than SPECT. In addition to relative perfusion, PET allows for assessing absolute quantitative coronary flow and flow reserve (CFR). CFR evaluates flow across the entire spectrum of myocardial perfusion from macrovascular to microvascular, from the epicardial arteries to the capillary level. Coronary microvascular dysfunction (CMD) is defined 
as functionally reduced CFR in the absence of flow-limiting $\mathrm{CAD}$ and is highly prevalent among at-risk individuals and is associated with adverse outcomes [50]. Impaired CFR is independently associated with cardiovascular risk and correlated with a higher non-obstructive CAD frequency in

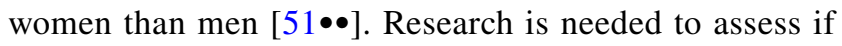
CMD and functional ischemia are good targets for future therapeutic interventions.

\section{CT Scan and Cardiac MRI}

Coronary computed tomography angiography (CCTA) can assess many causes of IHD in one test. It has high sensitivity and diagnostic accuracy for detecting and excluding CAD and coronary anomalies in both sexes [52]. A consensus statement from the Society of Cardiovascular Computed Tomography recommends the use of CCTA for symptomatic women as an effective tool for the evaluation of CAD [53].

Multicenter trials such as Prospective Multicenter Imaging Study for Evaluation of Chest Pain (PROMISE) and Scottish Computed Tomography of the Heart (SCOTHEART) demonstrated the ability of CCTA to improve clinical outcomes and established CCTA to be non-inferior to functional testing $[54,55]$. Further, CT fractional flow reserve utilizes computational fluid dynamics and can calculate the functional significance of coronary stenosis [56]. Unlike invasive angiography, CCTA helps accurately visualize phenomena such as non-calcified, non-obstructive plaque, and external remodeling. Early detection of plaque on CCTA leads to an increase in preventive therapies [53, 57•]. Additionally, entities such as SCAD or myocardial bridging are more readily characterized on three-dimensional CCTA over invasive coronary angiography. Concerns regarding radiation exposure limited utility; however with improved technology, there has been an $80 \%$ decrease in radiation dose over the last decade [58•]. In the emergency department, early utilization of CCTA can accurately identify low-risk patients, allowing for safe, cost-effective, and expedited discharge $[53,59]$.

Cardiovascular magnetic resonance imaging (CMR) is a comprehensive imaging modality that can provide a detailed CVD evaluation, including myocardial structure, function, viability, ischemia, and valvular heart disease. This test is a particularly appealing option in women with suspected CMD as there is no risk of exposure to ionizing radiation with high spatial resolution and diagnostic accuracy. Stress perfusion CMR is a diagnostic modality for SD.

In the Women's Ischemia Syndrome Evaluation (WISE) trial, which showed that women with non-obstructive coronary arteries INOCA had 2.5-3 times the risk of major adverse cardiovascular events (MACE) compared to women with normal coronary arteries $[60,61 \bullet \bullet]$, a myocardial perfusion reserve index of $<1.84$ had a $73 \%$ sensitivity and
$74 \%$ specificity to identify patients with abnormal coronary reactivity testing with a higher incidence of adverse events in those with abnormal myocardial perfusion imaging studies [62]. Given the high prevalence of myocardial infarction with non-obstructive coronary arteries (MINOCA) in women, CMR is an essential diagnostic tool that can reveal the diagnosis in up to $87 \%$ of these patients, including myocarditis and stress (Takotsubo) cardiomyopathy [63]. A recent study noted multimodality imaging (CMR and intravascular ultrasound [IVUS]) could identify the cause of MINOCA in $84.5 \%$ of women [64••].

\section{Angiography}

Among patients with angina presenting for cardiac catheterization, more than $20 \%$ have no angiographic evidence of CAD [65]. Despite this, most of these women experience persistent symptoms, recurrent hospitalizations, and poor functional status and undergo multiple catheterizations. These women have up to a three-fold increase in MACE incidence at 5 years, compared to asymptomatic controls [60, 65, 66]. Moreover, follow-up over 10 years showed cardiovascular death or MI occurs in as much as $12.8 \%$ of patients with non-obstructive disease [67]. Additional pathologic mechanisms to be considered include endothelial dysfunction, CMD, coronary spasm, oxygen-diffusion impairment, myocardial bridge, and angiographically nonevident plaques $[66,68]$. In more than a third of women with MINOCA, plaque rupture or ulceration was found on IVUS [69]. Even in patients with normal angiograms, IVUS confirms the presence of atherosclerosis in the vast majority $(80-100 \%)$ [64••, 69]. Positive remodeling and preserved lumen size were also common in women, limiting the utilization of angiograms [70]. Despite the absence of angiographic coronary disease, $44 \%$ had endothelial dysfunction detected by administering intracoronary acetylcholine, and $5 \%$ were found to have impaired fractional flow reserve of $\leq 0.80$ through coronary physiology assessments [65].

The Coronary Microvascular Angina (CorMicA) trial provided evidence that routine management guided by an interventional diagnostic procedure and stratified therapy improves patients' angina and quality of life [71 $\bullet$. The Coronary Vasomotion Disorders International Study (COVADIS) group proposed a practical consensus approach for FCA. FCA can diagnose whether the symptoms and ischemia are due to microvascular angina, vasospastic angina, obstructive epicardial coronary disease, CMD, or endothelial dysfunction. CMD can be further evaluated by a thorough investigation of the coronary artery response to vasoactive substances including adenosine and acetylcholine to determine if there is endothelial-dependent (decreased coronary blood flow $[\mathrm{CBF}]$ with intracoronary acetylcholine) or endothelial-independent dysfunction (decreased 
CBF with intracoronary adenosine) [71 $\bullet$, 72]. However, a study showed there can be significant overlap between all these mechanisms that can cause angina [73•].

Traditionally, women had higher rates of peri-procedural

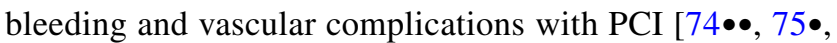
76•], which were strongly associated with higher MACE. The Study of Access Site for Enhancement of Percutaneous Coronary Intervention (SAFE-PCI) demonstrated that radial access site was feasible for women [74••]. Subsequent large RCTs have also supported the radial approach to reduce vascular complications and bleeding [77•].

The Dartmouth Dynamic Registry found that temporal changes in access site techniques and improvements in antithrombotic regimens have led to a decreased risk of bleeding and vascular complications in women. By 2016 there was no longer any difference between the sexes for vascular complications, although women still have higher rates of bleeding with PCI [78•]. Collaboration with interventional colleagues and utilizing this approach is essential in managing women with IHD.

\section{Treatments}

Women are less likely to receive GDMT compared with men with IHD [79•, 80, 81•]. Through research initiatives and the emergence of $\mathrm{HCW}$, there has been an improved understanding of sex-specific diagnosis and treatment of IHD in women. The discontinuation of harmful medications is equally essential for women with IHD. HRT such as estrogen with and without progesterone should be discontinued in the presence of IHD [82]. Research is ongoing to understand the role of HRT, if any, in CVD prevention. GDMT is followed for primary prevention of CVD in women, and these guidelines were summarized in 2020 [83••]. The following summarizes essential treatments for women. The 2014 guideline for stable IHD stated that there is a paucity in GDMT in special populations, such as women [84]. Figure 2 outlines treatment choices based predominantly on expert consensus for these conditions $[72,84,85 \bullet \bullet, 86]$.

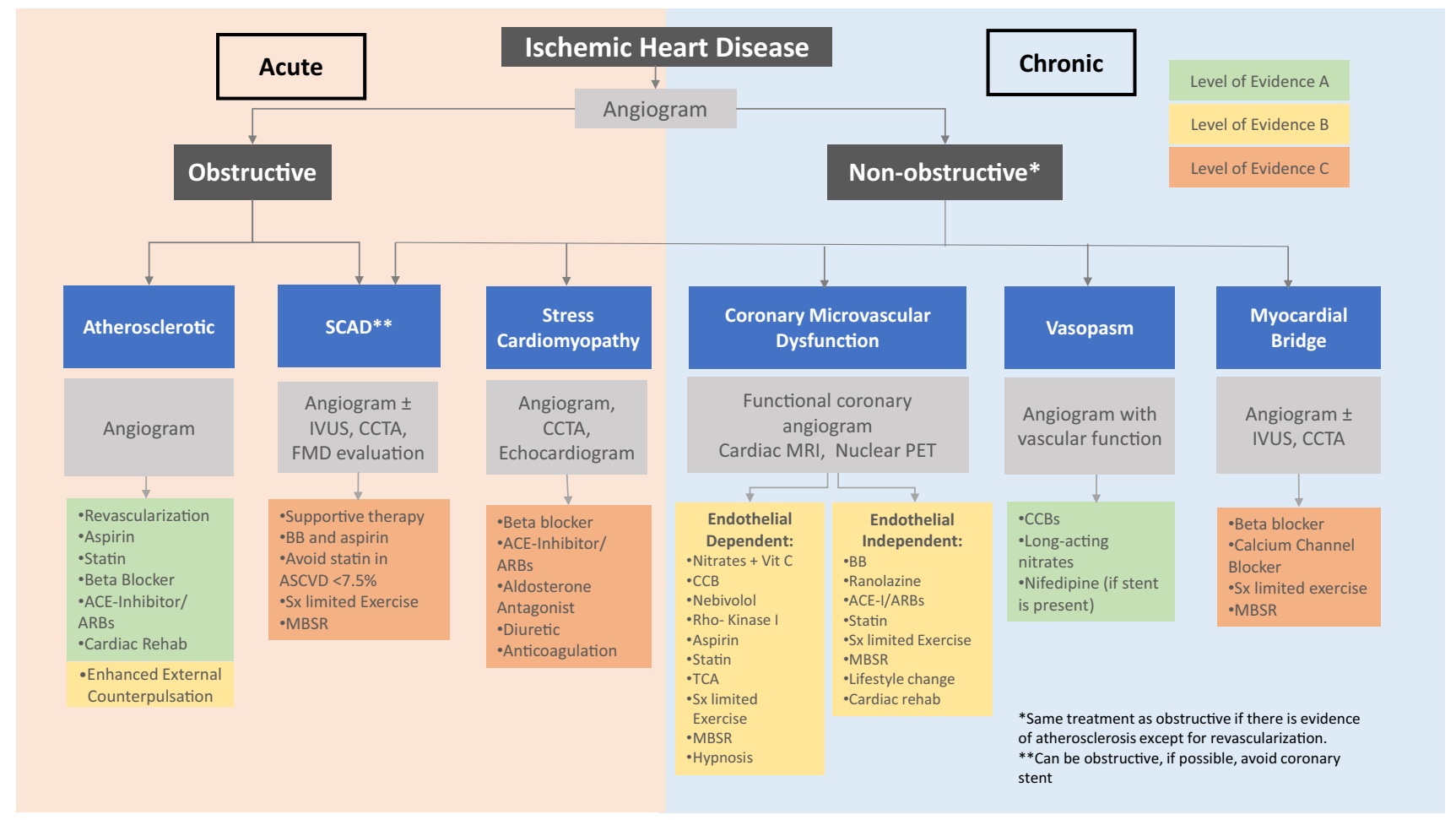

Fig. 2 Evaluation and management of ischemic heart disease with levels of evidence of the treatments. Abbreviations: ACE-I, angiotensin converting enzyme inhibitor; ARBs, angiotensin receptor blockers; BB, beta-blocker; CCB, calcium channel blocker; CCTA, cardiac computed tomography angiography; IVUS, intravascular ultrasound;
ENDO PAT, endothelial dysfunction Peripheral Arterial Tone; FMD, fibromuscular dysplasia; MBSR, mindfulness-based stress reduction; MRI, magnetic resonance imaging; PET, positron emission tomography; rehab, rehabilitation; SCAD, spontaneous coronary artery dissection; Sx, symptom; TCA, tricyclic antidepressants 


\section{Pharmacologic}

Low-dose aspirin (75-100 mg/day) may be considered for primary prevention in select women age 40-70 who are at higher ASCVD risk but who do not have an increased risk

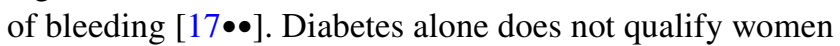
to be treated with aspirin [80, 87•]. The ACC/AHA 2019 guidelines on treating cholesterol recommended statins depending on their risk of MACE $[17 \bullet \bullet, 88]$. Women with a 10-year risk of atherosclerotic CVD (ASCVD) events $<7.5 \%$, should be evaluated for risk-enhancing factors including history of premature menopause ( $<40$ years); adverse pregnancy outcomes; high-risk race/ethnicity (e.g., South Asian ancestry); persistently elevated, primary hypertriglyceridemia ( $\geq 175 \mathrm{mg} / \mathrm{dL}$ ); elevated high-sensitivity C-reactive protein $(\geq 2.0 \mathrm{mg} / \mathrm{L})$; and elevated lipoprotein a $(\mathrm{Lp}(\mathrm{a}))(\mathrm{Lp}(\mathrm{a}) \geq 50 \mathrm{mg} / \mathrm{dL}$ or $\geq 125 \mathrm{nmol} / \mathrm{L})$. Shared decision-making to start aspirin and statins for primary preven-

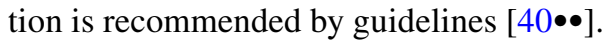

\section{Acute Coronary Syndrome}

There are established post-MI medications from RCTs. The 2014 ACC/AHA NSTEMI guidelines give a Class IA indication to use the same pharmacological agents in women and men for acute events and secondary prevention [82]. Delays in GDMT in women have led to an increased rate of readmission, reinfarction, and death in the first year after MI [79•, 80, 81•].

\section{Nonobstructive IHD}

Treatment of INOCA includes established anti-ischemic drugs such as nitrates, $\beta$-blockers (BB), calcium channel blockers (CCB), and angiotensin-converting enzyme inhibitors (ACEI). Statins are recommended as their anti-inflammatory properties improve endothelial function and angina when combined with anti-ischemic medications [89••]. Ranolazine and aminophylline have shown variable benefits (74). Prinzmetal's angina is treated with calcium channel blockers and nitrates [90•]. The Women's Ischemia Trial to Reduce Events in Nonobstructive CAD (WARRIOR) is currently enrolling 4422 symptomatic women and randomizing them to intensive ACEI, statin, and aspirin therapy vs. usual care to assess all-cause MACE over 3 years [91].

SCAD Patients presenting with SCAD had better early outcomes with conservative treatment with resolution of the dissection. PCI had higher risk of technical complications and propagation of the intramural hematoma and dissection. CABG was safe and effective in the short term but patients had high rates of graft occlusion due to the dissection resolving. Recurrence of SCAD was seen in $17 \%$, all in women, in one study. These patients are treated with long-term use of aspirin and BB and short-term use of clopidogrel. Beta-blockade has been associated with lowering

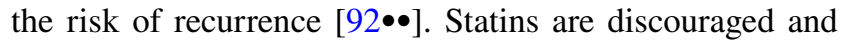
recommended only for appropriate ASCVD risk (10-year risk $\geq 7.5 \%$ ), as they have been associated with recurrent SCAD [93]. There are no RCTs, and these suggestions are mainly based on expert opinion.

\section{Myocardial Bridge}

BBs help symptoms by decreasing the artery's contractility and compression by decreasing heart rate and increasing diastolic filling time. If vasospasm is present, BBs should not be used alone. Nitrates are contraindicated because they worsen symptoms by vasodilating both the proximal and distal portions of the vessel adjacent to the bridge and increase

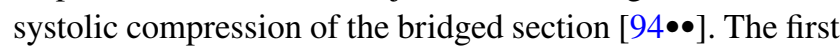
clinical trial with blinded treatment to BB (nebivolol), CCB (diltiazem) vs. placebo for IHD due to myocardial bridging is underway [95•].

\section{Stress Cardiomyopathy}

There is a 9:1 female to male preponderance in stress cardiomyopathy, especially in postmenopausal women. Studies have shown that endothelial dysfunction leading to epicardial or microvascular coronary spasm may be the pathogenic mechanism in stress cardiomyopathy [34•]. Anticoagulation is recommended if the left ventricular ejection fraction is $<30 \%$ until the akinesis or dyskinesis has resolved or for 3 months, whichever is shorter, and in patients with intraventricular thrombus until resolution [96•].

\section{Stents and CABG}

Revascularization, either with PCI or bypass surgery $(\mathrm{CABG})$, improves the quality of life and mortality risk when done in the appropriate clinical scenarios. Women undergoing stenting have more short-term procedural complications than men and suffer higher in-hospital bleeding, death, MI, and vascular complications. Radial vs. femoral access sites significantly decreased these complications in women [74••]. Long-term follow-up after stenting ( 20 months) shows that women tend to have decreased mortality compared to men [97].

CABG continues to be the treatment of multivessel CAD, especially in those with diabetes. Women undergoing CABG have higher mortality and post-operative complications despite having less coronary plaque burden preoperatively [98]. The increased mortality is more exaggerated at younger ages at the time of CABG than older patients. One large study illustrated a three-fold higher risk of death in women 
age $<50$, despite risk factor adjustment [99]. Alternate surgical techniques, such as off-pump bypass, have been shown to decrease this mortality and respiratory complications in women [100].

\section{Non-pharmacologic Treatments}

\section{Cardiac Rehabilitation}

Cardiac rehabilitation (CR) has Level 1A class recommendation as a mode of therapy to improve outcomes for patients after a cardiovascular event and cardiac surgery [82]. CR is underused despite substantial evidence-based research; women are in particular under-referred [101]. Of the women who were referred to CR, only $39 \%$ of women and $45 \%$ of men enroll and adherence was also found to be lower in women than men [102]. As a result, women are under-represented in research regarding $\mathrm{CR}$ leading to a paucity in sex-specific outcomes data [103••]. Alternatives to conventional CR, such as virtual/on-demand CR from the convenience of their home, are other options. Home-based CR programs are effective and safe [104•]. Increasing the participation in CR from 20 to $70 \%$ would save 25,000 lives and prevent 180,000 hospitalizations annually in the US [105•]. An integrated HCW team approach with established CR referral systems can deliver much-needed care to women with IHD. Additionally, in 2019 a perspective suggested that high-intensity interval training may be of greater benefit for women, with improved cardiovascular outcomes and mental health $[103 \bullet \bullet]$.

\section{Enhanced External Counterpulsation}

Existing data, mainly from uncontrolled studies, suggest a benefit from enhanced external counterpulsation (EECP) has a Class IIb recommendation for patients with angina refractory to other therapy [84]. Additional data from welldesigned RCTs are needed to better define this therapeutic strategy's role in patients with stable IHD.

\section{Multidisciplinary Team}

The role of HCW is to leverage multidisciplinary care to personalize IHD treatment for women. Our collective experience in utilizing a vast range of cardiovascular experts in intervention, imaging, HF, and prevention has been successful. Critical to the HCW team also includes primary care, psychology, nutrition, and exercise physiology. The broader team includes administrative, clinical, and research staff to bring translational research to clinical practice. We highlight the roles of a few members below since more detailed components of the programmatic development have been previously published $[8 \bullet \bullet]$.

Registered dietitian nutritionists (RDNs) provide tailored medical nutrition therapy (MNT) by assessing the patient's baseline nutrition status, comorbidities, and social determinants of health to provide behavioral change strategies that can lower TC and LDL-C by up to $13 \%$ [106••] and reduce relative CVD event risk by $20 \%$ [107•]. MNT in dyslipidemia results in cost savings related to reduced physician time, medication use ( $\$ 638$ to $\$ 1456$ per patient per year), and hospital readmission rates [106••]. RDNs help patients integrate nutrient-based research into whole foodbased, clinically and socioeconomically feasible strategies for individual patients. Furthermore, the expansion of telenutrition during the COVID-19 public health emergency has increased patient access to nutrition services integral to heart disease prevention.

Advanced practice providers (APPs) are integral members of the HCW team and often the first to encounter patients to

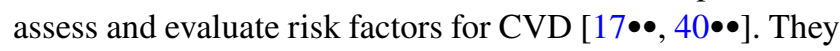
educate women regarding a heart-healthy diet and exercise, the foundation of cardiovascular health. APPs improve access to care, leading to improved clinical outcomes, more timely interventions, and patient satisfaction [108••].

Psychologists are critical in healthcare delivery at HCW. Women with IHD are more likely than women in the general population to experience psychological difficulties. The accumulation of evidence indicates that behavioral health interventions positively impact cardiac and mental health

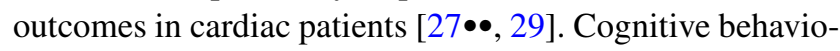
ral therapy is an effective treatment for depression, anxiety, panic disorder, trauma, lifestyle modification, and insomnia [109, 110•, 111]. Mindfulness-based stress reduction (MBSR) and biofeedback have positively affected cardiac conditions such as sinus tachycardia and reactive hypertension $[112,113 \bullet \bullet$. MBSR can be used in various manifestations of IHD (Fig. 2). Furthermore, behavioral health services embedded in the medical setting are associated with improved identification of behavioral health issues, medical adherence, quality of care, and lower utilization rates of acute healthcare services [114]. HCW address women's mental health to comprehensively improve CVD prevention, IHD recovery, and patients' quality of life.

\section{Conclusions}

Clinicians of HCW have a critical role in managing IHD in women, which remains the leading cause of CVD mortality. IHD in women is complex, requiring many clinical experts to address individual needs. HCW highlight the multidisciplinary approach utilized to manage these patients though outcomes data for these centers are still being investigated. 
Table 1 Summary of the role of heart centers for women in the management of ischemic heart disease

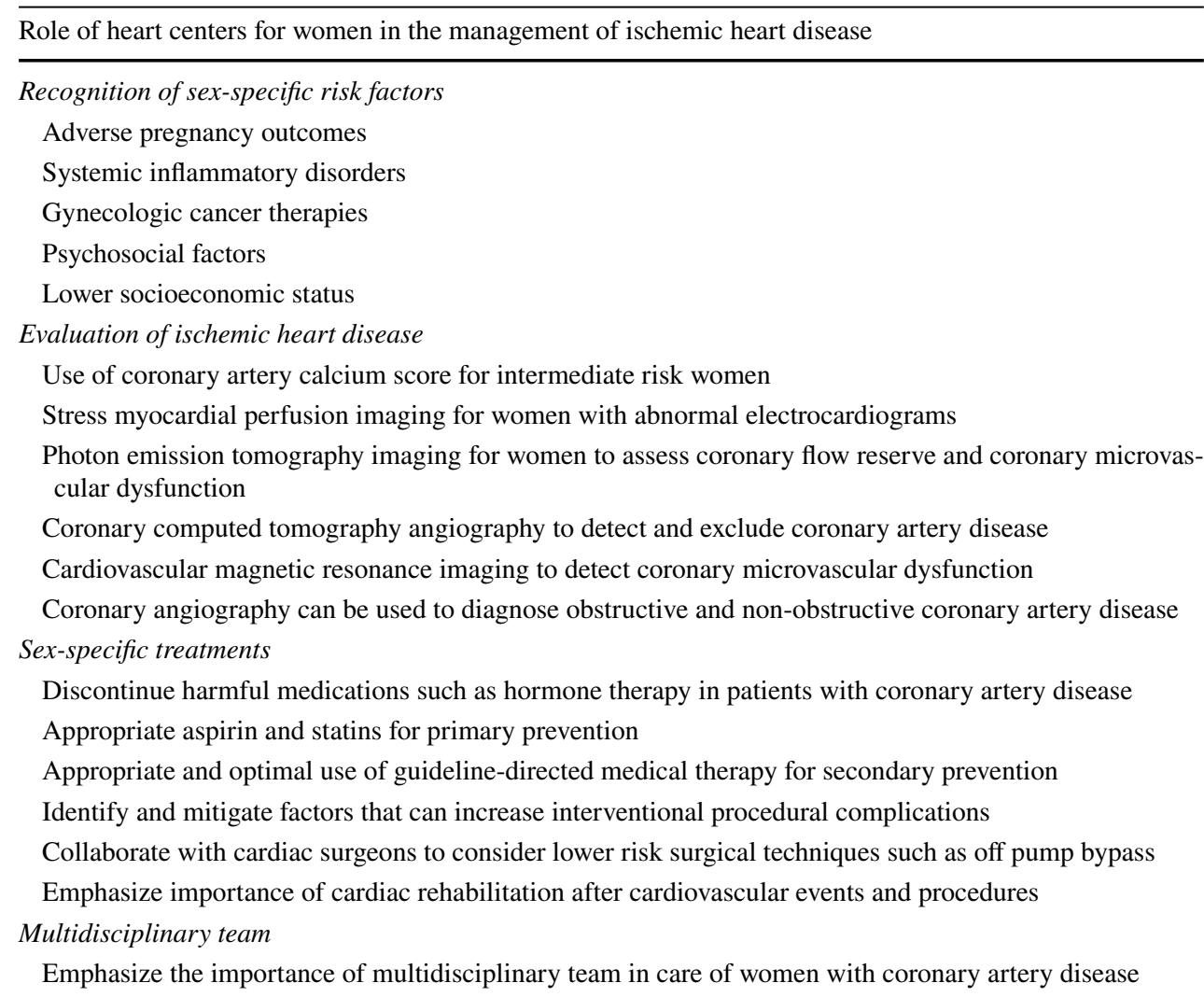

Table 1 is a summary of this review. Further work to determine the type of IHD and specific treatments is required. Sex-specific risk factors have been identified and multimodality cardiac imaging is improving in diagnosing IHD in women. Treatments are being studied to help improve symptoms and outcomes in women with IHD. There are no evidence-based guidelines in managing the various forms of CAD that are predominantly found in women, resulting from a lack of RCTs. HCW must continue to encourage and empower women to participate in research to determine what diagnostic approach and treatments will work best in improving their quality of life and outcomes.

Author Contribution All authors contributed to the literature review, writing, and editing of the document. Dr. Abha Khandelwal consolidated the first draft of the manuscript, and all authors commented on previous versions of the manuscript. All authors read and approved the final manuscript.

\section{Declarations}

Conflict of Interest No authors have any conflict of interest in writing this paper. The authors have no financial or proprietary interests in any material discussed in this article.

Bakir-consultant Amgen.

Khandelwal-Research Funding Novartis CTQJ.
Volgman-Research funding: NIH IND Number 119127; NIH NINR R01NR018443; Novartis CTQJ230A12001; Stock ownership: Apple, Inc.; MSD/Bayer Virtual Global Advisory Board Member, Bristol Myers Squibb Foundation Diverse Clinical Investigator Career Development Program (DCICDP) National Advisory Committee (NAC).

Human and Animal Rights and Informed Consent This article does not contain any studies with human or animal subjects performed by any of the authors.

\section{References}

Papers of particular interest, published recently, have been highlighted as:

- Of importance

$\bullet$ Of major importance

1.•• Roth GA, Mensah GA, Johnson CO, Addolorato G, Ammirati E, Baddour LM, et al. Global Burden of Cardiovascular Diseases and Risk Factors, 1990-2019: update from the GBD 2019 Study. J Am Coll Cardiol. 2020;76(25):2982-3021. https://doi.org/10. 1016/j.jacc.2020.11.010. This paper gives an update and a call to action for the increasing burden of cardiovascular disease and risk factors in both high-income and low-income countries.

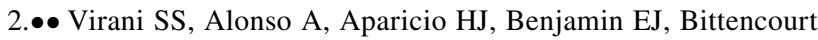
MS, Callaway CW et al. Heart disease and stroke statistics-2021 update: a report from the American Heart Association. 
Circulation. 2021: CIR0000000000000950. https://doi.org/10. 1161/CIR.0000000000000950. This annual statement paper gives the latest statistical update of mortality and morbidity caused by heart disease and strokes.

3. Stampfer MJ, Willett WC, Colditz GA, Rosner B, Speizer $\mathrm{FE}$, Hennekens $\mathrm{CH}$. A prospective study of postmenopausal estrogen therapy and coronary heart disease. N Engl J Med. 1985;313(17):1044-9. https://doi.org/10.1056/nejm198510 243131703

4. Wilson PWF, Garrison RJ, Castelli WP. Postmenopausal estrogen use, cigarette smoking, and cardiovascular morbidity in women over 50. N Engl J Med. 1985;313(17):1038-43. https:// doi.org/10.1056/nejm198510243131702.

5. Stampfer MJ, Colditz GA, Willett WC, Manson JE, Rosner B, Speizer FE et al. Postmenopausal estrogen therapy and cardiovascular disease. Ten-year follow-up from the Nurses' Health Study. N Engl J Med. 1991;325(11):756-62. https://doi.org/10. 1056/nejm199109123251102.

6. Hulley S, Grady D, Bush T, Furberg C, Herrington D, Riggs $B$ et al. Randomized trial of estrogen plus progestin for secondary prevention of coronary heart disease in postmenopausal women. Heart and Estrogen/progestin Replacement Study (HERS) Research Group. Jama. 1998;280(7):605-13. https:// doi.org/10.1001/jama.280.7.605.

7. Rossouw JE, Anderson GL, Prentice RL, LaCroix AZ, Kooperberg C, Stefanick ML, et al. Risks and benefits of estrogen plus progestin in healthy postmenopausal women: principal results from the Women's Health Initiative randomized controlled trial. JAMA. 2002;288(3):321-33. https://doi.org/10.1001/jama. 288.3.321.

8.• Lundberg GP, Mehta LS, Sanghani RM, Patel HN, Aggarwal NR, Aggarwal NT, et al. Heart centers for women: historical perspective on formation and future strategies to reduce cardiovascular disease. Circulation. 2018;138(11):1155-65. https://doi. org/10.1161/circulationaha.118.035351. This paper states the rationale and mission of heart centers for women.

9. National Heart Lung and Blood Institute. Women's heart health: developing a national health education action plan (No. 01-2963). Office of Prevention, Education, and Control: Silver Spring, MD, USA. 2001.

10. Mosca L, Appel LJ, Benjamin EJ, Berra K, Chandra-Strobos N, Fabunmi RP, et al. Evidence-based guidelines for cardiovascular disease prevention in women. J Am Coll Cardiol. 2004;43(5):900-21. https://doi.org/10.1016/j.jacc.2004.02.001.

11.• Peters SAE, Colantonio LD, Dai Y, Zhao H, Bittner V, Farkouh ME, Dluzniewski P, Poudel B, Muntner P, Woodward M. Trends in recurrent coronary heart disease after myocardial infarction among US women and men between 2008 and 2017. Circulation. 2021;143(7):650-60. https://doi.org/10.1161/CIRCULATIO NAHA.120.047065. Data analysis from Marketscan database from 2008-2017 evaluating rates of recurrent MI, recurrent CHD events, heart failure hospitalization, and mortality in the first year after an MI. These declined considerably between 2008 and 2017 in both men and women, with proportionally greater reductions for women than men.

12. Mosca L, Benjamin EJ, Berra K, Bezanson JL, Dolor RJ, Lloyd-Jones DM, et al. Effectiveness-based guidelines for the prevention of cardiovascular disease in women-2011 update: a guideline from the American Heart Association. Circulation. 2011;123(11):1243-62. https://doi.org/10.1161/CIR.0b013 e31820faaf8.

13. Pathak LA, Shirodkar S, Ruparelia R, Rajebahadur J. Coronary artery disease in women. Indian Heart J. 2017;69(4):532-8. https://doi.org/10.1016/j.ihj.2017.05.023.

14. Mehilli J, Presbitero P. Coronary artery disease and acute coronary syndrome in women. Heart. 2020;106(7):487-92. https:// doi.org/10.1136/heartjnl-2019-315555. This is a review of CAD and ACS in women which concluded that women with ACS frequently has ACS from non-atherosclerotic causes and that the younger aged women have a higher mortality rate even with evidence-based treatment for ACS.

15. Maas AH, Appelman YE. Gender differences in coronary heart disease. Netherlands heart journal: monthly journal of the Netherlands Society of Cardiology and the Netherlands Heart Foundation. 2010;18(12):598-602. https://doi.org/10.1007/ s12471-010-0841-y.

16. Wei J, Rooks C, Ramadan R, Shah AJ, Bremner JD, Quyyumi AA, et al. Meta-analysis of mental stress-induced myocardial ischemia and subsequent cardiac events in patients with coronary artery disease. Am J Cardiol. 2014;114(2):187-92. https://doi. org/10.1016/j.amjcard.2014.04.022.

17.•• Arnett DK, Blumenthal RS, Albert MA, Buroker AB, Goldberger ZD, Hahn EJ, et al. 2019 ACC/AHA guideline on the primary prevention of cardiovascular disease: a report of the American College of Cardiology/American Heart Association Task Force on Clinical Practice Guidelines. Circulation. 2019;140(11):e596-646. https://doi.org/10.1161/cir.0000000000 000678. This is an update of the guideline for primary prevention of CVD.

18. Geraghty L, Figtree GA, Schutte AE, Patel S, Woodward M, Arnott C. Cardiovascular disease in women: from pathophysiology to novel and emerging risk factors. Heart Lung Circ. 2021;30(1):9-17. https://doi.org/10.1016/j.hlc.2020.05.108. This review emphasizes the need for precision medicine based on sex and gender differences of risk factors for CVD.

19.• Schultz WM, Kelli HM, Lisko JC, Varghese T, Shen J, Sandesara $\mathrm{P}$, et al. Socioeconomic status and cardiovascular outcomes: challenges and interventions. Circulation. 2018;137(20):216678. https://doi.org/10.1161/CIRCULATIONAHA.117.029652.. This is a review of the impact of socioeconomic status on the outcomes of CVD including incidence and treatment in high-income societies. Sex disparities in cardiac care can be a result of income level, educational attainment, employment status, and neighborhood socioeconomic factors.

20. Hamad R, Penko J, Kazi DS, Coxson P, Guzman D, Wei PC, et al. Association of low socioeconomic status with premature coronary heart disease in US adults. JAMA cardiology. 2020. https://doi.org/10.1001/jamacardio.2020.1458. This is a computer simulation study based in the US population, which showed that disparities in coronary artery disease burden would not decrease unless the factors associated with low socioeconomic status are addressed.

21. Shaw LJ, Merz CN, Bittner V, Kip K, Johnson BD, Reis SE et al. Importance of socioeconomic status as a predictor of cardiovascular outcome and costs of care in women with suspected myocardial ischemia. Results from the National Institutes of Health, National Heart, Lung and Blood Institute-sponsored Women's Ischemia Syndrome Evaluation (WISE). Journal of women's health. 2008;17(7):1081-92. https://doi.org/10.1089/jwh.2007. 0596.

22. Creamer J, Mohanty A. United States Census Bureau. U.S. Poverty rate drops to $11.8 \%$ in 2018. https://www.census.gov/ library/stories/2019/09/poverty-rate-for-people-in-female-house holder-families-lowest-on-record.html. September 10, 2019. Accessed February 162021.

23. Safford MM, Reshetnyak E, Sterling MR, Richman JS, Muntner PM, Durant RW, et al. Number of social determinants of health and fatal and nonfatal incident coronary heart disease in the REGARDS Study. Circulation. 2021;143(3):244-53. https://doi. org/10.1161/CIRCULATIONAHA.120.048026.

24. Palacio A, Mansi R, Seo D, Suarez M, Garay S, Medina $\mathrm{H}$, et al. Social determinants of health score: does it help 
identify those at higher cardiovascular risk? Am J Manag Care. 2020;26(10):e312-8. https://doi.org/10.37765/ajmc.2020.88504.

25. Havranek EP, Mujahid MS, Barr DA, Blair IV, Cohen MS, CruzFlores S, et al. Social determinants of risk and outcomes for cardiovascular disease: a scientific statement from the American Heart Association. Circulation. 2015;132(9):873-98. https://doi. org/10.1161/CIR.0000000000000228.

26. White-Williams C, Rossi LP, Bittner VA, Driscoll A, Durant $\mathrm{RW}$, Granger BB, et al. Addressing social determinants of health in the care of patients with heart failure: a scientific statement from the American Heart Association. Circulation. 2020;141(22):e841-63. https://doi.org/10.1161/CIR.00000 00000000767.

27.• Levine GN, Cohen BE, Commodore-Mensah Y, Fleury J, Huffman JC, Khalid U et al. Psychological health, wellbeing, and the mind-heart-body connection: a scientific statement from the American Heart Association. Circulation. 2021:CIR0000000000000947. https://doi.org/10.1161/CIR. 0000000000000947. This scientific statement presents evidence that psychological health contributes to and causes CVD and that improving psychological health leads to better cardiovascular health. The paper offers simple screening measures that can be utilized by clinicians to assess psychological health and what tools can be used to help the patient.

28. Hasin DS, Sarvet AL, Meyers JL, Saha TD, Ruan WJ, Stohl M, et al. Epidemiology of adult DSM-5 major depressive disorder and its specifiers in the United States. JAMA Psychiat. 2018;75(4):336-46. https://doi.org/10.1001/jamapsychiatry. 2017.4602 .

29. Shanmugasegaram S, Russell KL, Kovacs AH, Stewart DE, Grace SL. Gender and sex differences in prevalence of major depression in coronary artery disease patients: a meta-analysis. Maturitas. 2012;73(4):305-11. https://doi.org/10.1016/j.matur itas.2012.09.005.

30. Orth-Gomer K, Schneiderman N, Wang HX, Walldin C, Blom M, Jernberg T. Stress reduction prolongs life in women with coronary disease: the Stockholm Women's Intervention Trial for Coronary Heart Disease (SWITCHD). Circ Cardiovasc Qual Outcomes. 2009;2(1):25-32. https://doi.org/10.1161/CIRCO UTCOMES.108.812859.

31. Gulliksson M, Burell G, Vessby B, Lundin L, Toss H, Svardsudd $\mathrm{K}$. Randomized controlled trial of cognitive behavioral therapy vs standard treatment to prevent recurrent cardiovascular events in patients with coronary heart disease: Secondary Prevention in Uppsala Primary Health Care project (SUPRIM). Arch Intern Med. 2011;171(2):134-40. https://doi.org/10.1001/archintern med.2010.510.

32.•• Naderi S, Tsai SA, Khandelwal A. Hypertensive disorders of pregnancy. Curr Atheroscler Rep. 2017;19(3):15. https://doi. org/10.1007/s11883-017-0648-z. This paper reviews the risk factors that contribute to the hypertension disorders during pregnancy. The authors summarize biomarkers that are helpful in managing patients with this problem and who should be treated with aspirin during pregnancy.

33.• American College of Obstetricians and Gynecologists' Presidential Task Force on P, Heart D, Committee on Practice B-O. ACOG Practice Bulletin No. 212: pregnancy and heart disease. Obstetrics and gynecology. 2019;133(5):e320-e56. https://doi. org/10.1097/AOG.0000000000003243. This report is from a great summary of the prevalence of heart disease during pregnancy and offers clinicians a comprehensive interpregnancy care plan for pregnant women with heart disease.

34. Patel H, Aggarwal NT, Rao A, Bryant E, Sanghani RM, Byrnes $\mathrm{M}$, et al. Microvascular disease and small-vessel disease: the nexus of multiple diseases of women. Journal of women's health. 2020;29(6):770-9. https://doi.org/10.1089/jwh.2019.
7826. This paper reviews the commonality of microvascular and small vessel disease that underlies many diseases that predominantly affect women including cardiovascular, endocrine, pregnancy-related, rheumatological, and neurological diseases.

35. Mehta PK, Wei J, Wenger NK. Ischemic heart disease in women: a focus on risk factors. Trends Cardiovasc Med. 2015;25(2):140 51. https://doi.org/10.1016/j.tcm.2014.10.005.

36. Kim ESH. Spontaneous coronary-artery dissection. N Engl J Med. 2020;383(24):2358-70. https://doi.org/10.1056/NEJMr a2001524.. This is a summary of epidemiology, presentation, and treatment of spontaneous coronary artery dissection (SCAD). It highlights the importance of concomitant systemic arteriopathy often accompanying this disease. It summarizes the diagnosis and treatment of non-coronary abnormalities that need to be considered to give comprehensive care to SCAD patients.

37. Polonsky TS, McClelland RL, Jorgensen NW, Bild DE, Burke GL, Guerci AD, et al. Coronary artery calcium score and risk classification for coronary heart disease prediction. JAMA. 2010;303(16):1610-6. https://doi.org/10.1001/jama.2010.461.

38. Hemal K, Pagidipati NJ, Coles A, Dolor RJ, Mark DB, Pellikka PA, et al. Sex differences in demographics, risk factors, presentation, and noninvasive testing in stable outpatients with suspected coronary artery disease: insights from the PROMISE trial. JACC Cardiovasc Imaging. 2016;9(4):337-46. https://doi. org/10.1016/j.jcmg.2016.02.001

39.• Shaw LJ, Min JK, Nasir K, Xie JX, Berman DS, Miedema MD, et al. Sex differences in calcified plaque and long-term cardiovascular mortality: observations from the CAC Consortium. Eur Heart J. 2018;39(41):3727-35. https://doi.org/10.1093/eurheartj/ ehy534. This is a large study of asymptomatic people who had coronary artery calcium (CAC) score determination. This study identifies sex differences in characteristics of atherosclerotic plaque that are associated with worse outcomes. This paper highlights the value of determining CAC detection to improve prevention and care of atherosclerosis.

40.• Grundy SM, Stone NJ, Bailey AL, Beam C, Birtcher KK, Blumenthal RS, et al. 2018 AHA/ACC/AACVPR/AAPA/ABC/ ACPM/ADA/AGS/APhA/ASPC/NLA/PCNA guideline on the management of blood cholesterol: a report of the American College of Cardiology/American Heart Association Task Force on Clinical Practice Guidelines. J Am Coll Cardiol. 2019;73(24):e285-350. https://doi.org/10.1016/j.jacc.2018. 11.003. This guideline addresses parameters of cholesterol measurement, influence of calculated ASCVD risk, management, and therapeutic modalities as well as the safety and side effects of statins.

41. Messenger B, Li D, Nasir K, Carr JJ, Blankstein R, Budoff MJ Coronary calcium scans and radiation exposure in the multiethnic study of atherosclerosis. Int $\mathbf{J}$ Cardiovasc Imaging. 2016;32(3):525-9. https://doi.org/10.1007/s10554-015-0799-3.

42. deGoma EM, Karlsberg RP, Judelson DR, Budoff MJ. The underappreciated impact of heart disease. Women's health issues: official publication of the Jacobs Institute of Women's Health. 2010;20(5):299-303. https://doi.org/10.1016/j.whi.2010. 05.001 .

43. Dolor RJ, Patel MR, Melloni C, Chatterjee R, McBroom AJ, Musty MD et al. Noninvasive technologies for the diagnosis of coronary artery disease in women. AHRQ Comparative Effectiveness Reviews. Rockville (MD)2012.

44.• Aggarwal NR, Patel HN, Mehta LS, Sanghani RM, Lundberg GP, Lewis SJ, et al. Sex differences in ischemic heart disease: advances, obstacles, and next steps. Circ Cardiovasc Qual Outcomes. 2018;11(2): e004437. https://doi.org/10.1161/CIRCO UTCOMES.117.004437. This document emphasizes the 
importance of considering sex differences in ischemic heart disease to improve outcomes in women.

45. Standbridge K, Reyes E. The role of pharmacological stress testing in women. Journal of nuclear cardiology: official publication of the American Society of Nuclear Cardiology. 2016;23(5):9971007. https://doi.org/10.1007/s12350-016-0602-4.

46. Wolk MJ, Bailey SR, Doherty JU, Douglas PS, Hendel RC, Kramer CM, et al. ACCF/AHA/ASE/ASNC/HFSA/HRS/ SCAI/SCCT/SCMR/STS 2013 multimodality appropriate use criteria for the detection and risk assessment of stable ischemic heart disease: a report of the American College of Cardiology Foundation Appropriate Use Criteria Task Force, American Heart Association, American Society of Echocardiography, American Society of Nuclear Cardiology, Heart Failure Society of America, Heart Rhythm Society, Society for Cardiovascular Angiography and Interventions, Society of Cardiovascular Computed Tomography, Society for Cardiovascular Magnetic Resonance, and Society of Thoracic Surgeons. J Am Coll Cardiol. 2014;63(4):380-406. https://doi.org/10.1016/j.jacc.2013. 11.009 .

47. Mieres JH, Shaw LJ, Arai A, Budoff MJ, Flamm SD, Hundley WG, et al. Role of noninvasive testing in the clinical evaluation of women with suspected coronary artery disease: consensus statement from the Cardiac Imaging Committee, Council on Clinical Cardiology, and the Cardiovascular Imaging and Intervention Committee, Council on Cardiovascular Radiology and Intervention. American Heart Association Circulation. 2005;111(5):682-96. https://doi.org/10.1161/01.CIR.00001 55233.67287 .60 .

48.• Taqueti VR, Dorbala S, Wolinsky D, Abbott B, Heller GV, Bateman TM, et al. Myocardial perfusion imaging in women for the evaluation of stable ischemic heart disease-state-of-the-evidence and clinical recommendations. Journal of nuclear cardiology: official publication of the American Society of Nuclear Cardiology. 2017;24(4):1402-26. https://doi.org/10.1007/s12350017-0926-8. This is an updated consensus statement from the American Society of Nuclear Cardiology, which highlights the new modalities to be considered when ordering stress tests in women. The use of detecting coronary flow reserve (CFR) with positron emission tomography (PET) to risk stratify women with coronary microvascular dysfunction or non-obstructive CAD is discussed.

49. Mieres JH, Gulati M, Bairey Merz N, Berman DS, Gerber TC, Hayes SN, et al. Role of noninvasive testing in the clinical evaluation of women with suspected ischemic heart disease: a consensus statement from the American Heart Association. Circulation. 2014;130(4):350-79. https://doi.org/10.1161/CIR.0000000000 000061.

50. Murthy VL, Naya M, Taqueti VR, Foster CR, Gaber M, Hainer $\mathrm{J}$, et al. Effects of sex on coronary microvascular dysfunction and cardiac outcomes. Circulation. 2014;129(24):2518-27. https:// doi.org/10.1161/CIRCULATIONAHA.113.008507.

51.•• Taqueti VR, Shaw LJ, Cook NR, Murthy VL, Shah NR, Foster $\mathrm{CR}$, et al. Excess cardiovascular risk in women relative to men referred for coronary angiography is associated with severely impaired coronary flow reserve, not obstructive disease. Circulation. 2017;135(6):566-77. https://doi.org/10.1161/CIRCU LATIONAHA.116.023266. This is a study that highlights the importance of determining coronary flow reserve in patients with non-obstructive coronary artery disease. Women, but not men, with severely impaired CFR had higher risk of cardiovascular events.

52. Budoff MJ, Dowe D, Jollis JG, Gitter M, Sutherland J, Halamert E, et al. Diagnostic performance of 64-multidetector row coronary computed tomographic angiography for evaluation of coronary artery stenosis in individuals without known coronary artery disease: results from the prospective multicenter ACC URACY (Assessment by Coronary Computed Tomographic Angiography of Individuals Undergoing Invasive Coronary Angiography) trial. J Am Coll Cardiol. 2008;52(21):1724-32. https://doi.org/10.1016/j.jacc.2008.07.031.

53. Truong QA, Rinehart S, Abbara S, Achenbach S, Berman DS, Bullock-Palmer R, et al. Coronary computed tomographic imaging in women: an expert consensus statement from the Society of Cardiovascular Computed Tomography. J Cardiovasc Comput Tomogr. 2018;12(6):451-66. https://doi.org/10.1016/j.jcct.2018. 10.019 .

54. Douglas PS, Hoffmann U, Patel MR, Mark DB, Al-Khalidi $\mathrm{HR}$, Cavanaugh B, et al. Outcomes of anatomical versus functional testing for coronary artery disease. N Engl J Med. 2015;372(14):1291-300. https://doi.org/10.1056/NEJMoa1415 516.

55. SCOT-HEART Investigators. CT coronary angiography in patients with suspected angina due to coronary heart disease (SCOT-HEART): an open-label, parallel-group, multicentre trial. Lancet. 2015;385(9985):2383-91. https://doi.org/10.1016/ S0140-6736(15)60291-4.

56. Norgaard BL, Leipsic J, Gaur S, Seneviratne S, Ko BS, Ito H, et al. Diagnostic performance of noninvasive fractional flow reserve derived from coronary computed tomography angiography in suspected coronary artery disease: the NXT trial (Analysis of Coronary Blood Flow Using CT Angiography: Next Steps). J Am Coll Cardiol. 2014;63(12):1145-55. https://doi.org/ 10.1016/j.jacc.2013.11.043.

57. Foy AJ, Dhruva SS, Peterson B, Mandrola JM, Morgan DJ, Redberg RF. Coronary computed tomography angiography vs functional stress testing for patients with suspected coronary artery disease: a systematic review and meta-analysis. JAMA Intern Med. 2017;177(11):1623-31. https://doi.org/10.1001/ jamainternmed.2017.4772. This is a meta-analysis of coronary computed tomography angiography (CCTA) studies, which found that CCTA is associated with a decrease in myocardial infarctions. However, the use of CCTA increased the use of invasive coronary angiograms, revascularizations, and new diagnoses of coronary artery disease and increased the use of preventive therapies such as aspirin and statins.

58. Stocker TJ, Deseive S, Leipsic J, Hadamitzky M, Chen MY, Rubinshtein $\mathrm{R}$, et al. Reduction in radiation exposure in cardiovascular computed tomography imaging: results from the PROspective multicenter registry on radiaTion dose Estimates of cardiac CT angIOgraphy iN daily practice in 2017 (PROTECTION VI). Eur Heart J. 2018;39(41):3715-23. https://doi.org/10. 1093/eurheartj/ehy546. This is a large international radiation dose survey, which showed that a decrease in radiation exposure over the past decade from cardiac computed tomography angiography (CCTA). However, there is still variability in radiation exposure in different sites; more training and adaptation of more current cardiac scan protocols are needed.

59. Lubbers M, Dedic A, Coenen A, Galema T, Akkerhuis J, Bruning $\mathrm{T}$, et al. Calcium imaging and selective computed tomography angiography in comparison to functional testing for suspected coronary artery disease: the multicentre, randomized CRESCENT trial. Eur Heart J. 2016;37(15):1232-43. https:// doi.org/10.1093/eurheartj/ehv700.

60. Johnson BD, Shaw LJ, Buchthal SD, Bairey Merz CN, Kim HW, Scott KN, et al. Prognosis in women with myocardial ischemia in the absence of obstructive coronary disease: results from the National Institutes of Health-National Heart, Lung, and Blood Institute-Sponsored Women's Ischemia Syndrome Evaluation (WISE). Circulation. 2004;109(24):2993-9. https://doi.org/10. 1161/01.Cir.0000130642.79868.B2. 
61.• Herscovici R, Sedlak T, Wei J, Pepine CJ, Handberg E, Bairey Merz CN. Ischemia and no obstructive coronary artery disease (INOCA): what is the risk? Journal of the American Heart Association. 2018;7(17):e008868. https://doi.org/10.1161/jaha.118. 008868. This paper highlights the lack and need for evidencebased treatment guidelines for patients with INOCA.

62. Doyle M, Weinberg N, Pohost GM, Bairey Merz CN, Shaw LJ, Sopko G, et al. Prognostic value of global MR myocardial perfusion imaging in women with suspected myocardial ischemia and no obstructive coronary disease: results from the NHLBIsponsored WISE (Women's Ischemia Syndrome Evaluation) study. JACC Cardiovasc Imaging. 2010;3(10):1030-6. https:// doi.org/10.1016/j.jcmg.2010.07.008.

63. Pathik B, Raman B, Mohd Amin NH, Mahadavan D, Rajendran S, McGavigan AD, et al. Troponin-positive chest pain with unobstructed coronary arteries: incremental diagnostic value of cardiovascular magnetic resonance imaging. Eur Heart J Cardiovasc Imaging. 2016;17(10):1146-52. https://doi.org/10.1093/ ehjci/jev289.

64.• Reynolds HR, Maehara A, Kwong RY, Sedlak T, Saw J, Smilowitz NR, Mahmud E, Wei J, Marzo K, Matsumura M, Seno A, Hausvater A, Giesler C, Jhalani N, Toma C, Har B, Thomas D, Mehta LS, Trost J, Mehta PK, Ahmed B, Bainey KR, Xia Y, Shah B, Attubato M, Bangalore S, Razzouk L, Ali ZA, Merz NB, Park K, Hada E, Zhong H, Hochman JS. Coronary optical coherence tomography and cardiac magnetic resonance imaging to determine underlying causes of myocardial infarction with nonobstructive coronary arteries in women. Circulation. 2021;143(7):624-40. https://doi.org/10.1161/CIRCULATIO NAHA.120.052008. Prospective observational trial enrolling 300 women with MINOCA. Multimodality imaging with coronary OCT and CMR identified potential mechanisms in $84.5 \%$ of women with a diagnosis of MINOCA, $75.5 \%$ of which were ischemic and $24.5 \%$ of which were non-ischemic, alternate diagnoses to myocardial infarction.

65. Lee BK, Lim HS, Fearon WF, Yong AS, Yamada R, Tanaka $\mathrm{S}$, et al. Invasive evaluation of patients with angina in the absence of obstructive coronary artery disease. Circulation. 2015;131(12):1054-60. https://doi.org/10.1161/circulationaha. 114.012636.

66. Pepine CJ, Ferdinand KC, Shaw LJ, Light-McGroary KA, Shah RU, Gulati M, et al. Emergence of nonobstructive coronary artery disease: a woman's problem and need for change in definition on angiography. J Am Coll Cardiol. 2015;66(17):1918-33. https://doi.org/10.1016/j.jacc.2015.08.876.

67. Sharaf B, Wood T, Shaw L, Johnson BD, Kelsey S, Anderson $\mathrm{RD}$, et al. Adverse outcomes among women presenting with signs and symptoms of ischemia and no obstructive coronary artery disease: findings from the National Heart, Lung, and Blood Institute-sponsored Women's Ischemia Syndrome Evaluation (WISE) angiographic core laboratory. Am Heart J. 2013;166(1):134-41. https://doi.org/10.1016/j.ahj.2013.04.002.

68. Likoff W, Segal BL, Kasparian H. Paradox of normal selective coronary arteriograms in patients considered to have unmistakable coronary heart disease. N Engl J Med. 1967;276(19):1063-6. https://doi.org/10.1056/nejm196705112761904.

69. Reynolds HR, Srichai MB, Iqbal SN, Slater JN, Mancini GB, Feit $\mathrm{F}$, et al. Mechanisms of myocardial infarction in women without angiographically obstructive coronary artery disease. Circulation. 2011;124(13):1414-25. https://doi.org/10.1161/ circulationaha.111.026542.

70. Khuddus MA, Pepine CJ, Handberg EM, Bairey Merz CN, Sopko G, Bavry AA, et al. An intravascular ultrasound analysis in women experiencing chest pain in the absence of obstructive coronary artery disease: a substudy from the National Heart, Lung and Blood Institute-Sponsored Women's Ischemia
Syndrome Evaluation (WISE). J Interv Cardiol. 2010;23(6):5119. https://doi.org/10.1111/j.1540-8183.2010.00598.x.

71. Ford TJ, Ong P, Sechtem U, Beltrame J, Camici PG, Crea F, et al. Assessment of vascular dysfunction in patients without obstructive coronary artery disease: why, how, and when. JACC Cardiovasc Interv. 2020;13(16):1847-64. https://doi.org/10.1016/j.jcin. 2020.05.052. This article reviews the indications, rationale, and methods for the invasive assessment of coronary vascular dysfunction.

72. Samim A, Nugent L, Mehta PK, Shufelt C, Bairey Merz CN. Treatment of angina and microvascular coronary dysfunction. Curr Treat Options Cardiovasc Med. 2010;12(4):355-64. https:// doi.org/10.1007/s11936-010-0083-8.

73. Kumar S, Mehta PK, Eshtehardi P, Hung OY, Koh JS, Kumar A, et al. Functional coronary angiography in symptomatic patients with no obstructive coronary artery disease. Catheterization and cardiovascular interventions: official journal of the Society for Cardiac Angiography \& Interventions. 2020. https://doi.org/10. 1002/ccd.29237. This study found that there is significant overlap in the mechanisms of ischemia that can cause angina.

74.• Rymer JA, Kaltenbach LA, Kochar A, Hess CN, Gilchrist IC, Messenger JC, et al. Comparison of rates of bleeding and vascular complications before, during, and after trial enrollment in the SAFE-PCI trial for women. Circ Cardiovasc Interv. 2019;12(5): e007086. https://doi.org/10.1161/circinterventions.118.007086. This study showed significant decrease in complications in women undergoing PCI using the radial versus femoral artery access.

75. Alkhouli M, Alqahtani F, Elsisy MF, Kawsara A, Alasnag M. Incidence and outcomes of acute ischemic stroke following percutaneous coronary interventions in men versus women. Am J Cardiol. 2020;125(3):336-40. https://doi.org/10.1016/j.amjca rd.2019.10.045. A study of the National Inpatient Sample database from 2003 to 2016 found women are more likely to suffer post-PCI stroke than males regardless of the PCI indication. Among those with post-PCI strokes, women have higher adjusted rates of vascular complications and blood transfusion.

76. Kosmidou I, Leon MB, Zhang Y, Serruys PW, von Birgelen C, Smits PC, et al. Long-term outcomes in women and men following percutaneous coronary intervention. J Am Coll Cardiol. 2020;75(14):1631-40. https://doi.org/10.1016/j.jacc.2020.01. 056. A large-scale, individual patient data pooled analysis of contemporary percutaneous coronary intervention (PCI) trials found that women had a higher risk of major adverse cardiovascular events and ischemia-driven target lesion revascularization compared with men at 5 years following PCI.

77. Guo Y, Yin F, Fan C, Wang Z. Gender difference in clinical outcomes of the patients with coronary artery disease after percutaneous coronary intervention: a systematic review and meta-analysis. Medicine (Baltimore). 2018;97(30): e11644. https://doi.org/10.1097/md.0000000000011644. A systematic review and meta-analysis of 49 studies, involving $1,032,828$ patients which showed that the prognosis of male patients with coronary artery disease after percutaneous coronary intervention is better than that of females, except for longterm revascularization.

78. Chaudry HI, Lee J, Li SX, Gasperetti A, Lee KM, Zbib NH et al. Sex differences in acute bleeding and vascular complications following percutaneous coronary intervention between 2003 and 2016: trends from the Dartmouth Dynamic Registry. Cardiovascular revascularization medicine : including molecular interventions. 2020.https://doi.org/10.1016/j.carrev.2020.07.028. This registry of consecutive percutaneous coronary interventions (PCI) found that the incidence of bleeding and vascular 
complications fell between 2003 and 2016 in both men and women and there was no longer any difference between the sexes for this outcome. Although bleeding following PCI has decreased in both sexes over time, women compared to men, continued to have more bleeding.

79. Zhao M, Vaartjes I, Graham I, Grobbee D, Spiering W, Klipstein-Grobusch K, et al. Sex differences in risk factor management of coronary heart disease across three regions. Heart. 2017;103(20):1587-94. https://doi.org/10.1136/heartjnl-2017311429. This study demonstrated that women in Europe and the Middle East were overall less likely to have optimized risk factor management than men, as opposed to in Asia, where women were more likely than men to reach lifestyle targets.

80. Garcia M, Mulvagh SL, Merz CN, Buring JE, Manson JE. Cardiovascular disease in women: clinical perspectives. Circ Res. 2016;118(8):1273-93. https://doi.org/10.1161/CIRCRESAHA. 116.307547.

81.• Hyun KK, Redfern J, Patel A, Peiris D, Brieger D, Sullivan D, et al. Gender inequalities in cardiovascular risk factor assessment and management in primary healthcare. Heart. 2017;103(7):4928. https://doi.org/10.1136/heartjnl-2016-310216. This article showed that the measurement of cardiovascular disease risk factors was lower in Australian women receiving primary healthcare services than men. Additionally, women with high-risk CVD were more likely to be on GDMT than younger women compared to male counterparts.

82. Amsterdam EA, Wenger NK, Brindis RG, Casey DE Jr, Ganiats TG, Holmes DR Jr, et al. 2014 AHA/ACC guideline for the management of patients with non-ST-elevation acute coronary syndromes: a report of the American College of Cardiology/ American Heart Association Task Force on Practice Guidelines. J Am Coll Cardiol. 2014;64(24):e139-228. https://doi.org/10. 1016/j.jacc.2014.09.017.

83.• Cho L, Davis M, Elgendy I, Epps K, Lindley KJ, Mehta PK, et al. Summary of updated recommendations for primary prevention of cardiovascular disease in women: JACC state-of-the-art review. J Am Coll Cardiol. 2020;75(20):2602-18. https://doi. org/10.1016/j.jacc.2020.03.060. This guideline update summarizes new data on the prevention of CVD in women with an emphasis on sex-related risk factors, perimenopausal hormone therapy, hypertension, diabetes, anticoagulation and psychosocial issues.

84. Fihn SD, Blankenship JC, Alexander KP, Bittl JA, Byrne JG, Fletcher BJ, et al. 2014 ACC/AHA/AATS/PCNA/SCAI/STS focused update of the guideline for the diagnosis and management of patients with stable ischemic heart disease: a report of the American College of Cardiology/American Heart Association Task Force on Practice Guidelines, and the American Association for Thoracic Surgery, Preventive Cardiovascular Nurses Association, Society for Cardiovascular Angiography and Interventions, and Society of Thoracic Surgeons. J Am Coll Cardiol. 2014;64(18):1929-49. https://doi.org/10.1016/j.jacc. 2014.07.017.

85.•• Knuuti J, Wijns W, Saraste A, Capodanno D, Barbato E, FunckBrentano C, et al. 2019 ESC Guidelines for the diagnosis and management of chronic coronary syndromes. Eur Heart J. 2020;41(3):407-77. https://doi.org/10.1093/eurheartj/ehz425. This is the most current European guidelines for stable ischemic heart disease.

86. Thomas GR, DiFabio JM, Gori T, Parker JD. Once daily therapy with isosorbide-5-mononitrate causes endothelial dysfunction in humans: evidence of a free-radical-mediated mechanism. J Am Coll Cardiol. 2007;49(12):1289-95. https://doi.org/10.1016/j. jacc.2006.10.074.

87. Gaziano JM, Brotons C, Coppolecchia R, Cricelli C, Darius $\mathrm{H}$, Gorelick PB, et al. Use of aspirin to reduce risk of initial vascular events in patients at moderate risk of cardiovascular disease (ARRIVE): a randomised, double-blind, placebo-controlled trial. Lancet. 2018;392(10152):1036-46. https://doi. org/10.1016/S0140-6736(18)31924-X. This RCT studied the use of aspirin in the primary prevention of cardiovascular events in moderate risk patients, finding an increased risk of bleeding and no difference in the incidence of adverse events.

88. Stone NJ, Robinson JG, Lichtenstein AH, Bairey Merz CN, Blum $\mathrm{CB}$, Eckel RH et al. 2013 ACC/AHA guideline on the treatment of blood cholesterol to reduce atherosclerotic cardiovascular risk in adults: a report of the American College of Cardiology/ American Heart Association Task Force on Practice Guidelines. Journal of the American College of Cardiology. 2014;63(25 Pt B):2889-934. https://doi.org/10.1016/j.jacc.2013.11.002.

89.• Bairey Merz CN, Pepine CJ, Shimokawa H, Berry C. Treatment of coronary microvascular dysfunction. Cardiovasc Res. 2020;116(4):856-70. https://doi.org/10.1093/cvr/cvaa006. This article reviews the evidence of pharmacotherapy in patients with coronary microvascular dysfunction, where the combined use of statins with ACEi or ARB is particularly beneficial.

90.• Hubert A, Seitz A, Pereyra VM, Bekeredjian R, Sechtem U, Ong P. Coronary artery spasm: the interplay between endothelial dysfunction and vascular smooth muscle cell hyperreactivity. European cardiology. 2020;15: e12. https://doi.org/10.15420/ecr. 2019.20. This article reviews the possible mechanistic interplay between an impaired endothelial and VSMC function in the pathogenesis of CAS.

91. ClinicalTrials.gov [Internet]. Bethesda (MD): National Library of Medicine (US). January 31, 2018: ClinicalTrials.gov Identifier: NCT03417388 Women's IschemiA TRial to Reduce Events In Non-ObstRuctive CAD (WARRIOR). Available from: https:// clinicaltrials.gov/ct2/show/NCT03417388.2018.

92.• Saw J, Humphries K, Aymong E, Sedlak T, Prakash R, Starovoytov $\mathrm{A}$, et al. Spontaneous coronary artery dissection: clinical outcomes and risk of recurrence. J Am Coll Cardiol. 2017;70(9):1148-58. https://doi.org/10.1016/j.jacc.2017.06.053. This study prospectively follow 327 SCAD patients median follow-up was 3 years. It looked at recurrence of Recurrent SCAD occurred in $10.4 \%$ of patients.

93. Tweet MS, Hayes SN, Pitta SR, Simari RD, Lerman A, Lennon RJ, et al. Clinical features, management, and prognosis of spontaneous coronary artery dissection. Circulation. 2012;126(5):579-88. https://doi.org/10.1161/CIRCULATIO NAHA.112.105718

94.•• Teragawa H, Oshita C, Ueda T. The myocardial bridge: potential influences on the coronary artery vasculature. Clinical Medicine Insights Cardiology. 2019;13:1179546819846493. https://doi. org/10.1177/1179546819846493. This review focuses on the pathophysiology and diagnosis of MB and MB-related cardiovascular diseases, including coronary spasm, and on the treatment strategies for MB.

95.• ClinicalTrials.gov [Internet]. Bethesda (MD): National Library of Medicine (US). October 17, 2019. Identifier: NCT04130438 efficacy of medical therapy in women and men with angina and myocardial bridging. Available from: https://clinicaltrials.gov/ ct2/show/NCT04130438. 2019. Accessed February 162021. This is a clinical trial enrolling patients with myocardial bridging and randomizing them to nebivolol, diltiazem or placebo.

96. Medina de Chazal H, Del Buono MG, Keyser-Marcus L, Ma L, Moeller FG, Berrocal D et al. Stress cardiomyopathy diagnosis and treatment: JACC state-of-the-art review. Journal of the American College of Cardiology. 2018;72(16):1955-71. https://doi.org/10.1016/j.jacc.2018.07.072. This is a review 
of the current presentation, diagnosis, and management of patients with stress cardiomyopathy.

97. Anderson ML, Peterson ED, Brennan JM, Rao SV, Dai D, Anstrom KJ, et al. Short- and long-term outcomes of coronary stenting in women versus men: results from the National Cardiovascular Data Registry Centers for Medicare \& Medicaid services cohort. Circulation. 2012;126(18):2190-9. https://doi. org/10.1161/circulationaha.112.111369.

98. Edwards FH, Carey JS, Grover FL, Bero JW, Hartz RS. Impact of gender on coronary bypass operative mortality. Ann Thorac Surg. 1998;66(1):125-31. https://doi.org/10.1016/s00034975(98)00358-0.

99. Vaccarino V, Abramson JL, Veledar E, Weintraub WS. Sex differences in hospital mortality after coronary artery bypass surgery: evidence for a higher mortality in younger women. Circulation. 2002;105(10):1176-81. https://doi.org/10.1161/hc1002. 105133.

100. Brown PP, Mack MJ, Simon AW, Battaglia S, Tarkington L, Horner $\mathrm{S}$ et al. Outcomes experience with off-pump coronary artery bypass surgery in women. The Annals of thoracic surgery. 2002;74(6):2113-9; discussion 20. https://doi.org/10.1016/ s0003-4975(02)03988-7.

101. Samayoa L, Grace SL, Gravely S, Scott LB, Marzolini S, Colella TJ. Sex differences in cardiac rehabilitation enrollment: a metaanalysis. Can J Cardiol. 2014;30(7):793-800. https://doi.org/10. 1016/j.cjca.2013.11.007.

102. Bennett AL, Lavie CJ, Grace SL. Cardiac rehabilitation following acute coronary syndrome in women. Curr Treat Options Cardiovasc Med. 2017;19(8):57. https://doi.org/10.1007/ s11936-017-0559-x.

103.• Way KL, Reed JL. Meeting the needs of women in cardiac rehabilitation. Circulation. 2019;139(10):1247-8. https://doi. org/10.1161/circulationaha.118.037754. This is a perspective piece on studying women to undergo $\mathrm{CR}$. It highlights some data on HIIT to improve CV and mental health in women.

104. Choxi R, Kolominsky J, Al Rifai M, Patel J, Shapiro MD. Cardiac rehabilitation and implications during the COVID-19 era https://www.acc.org/latest-in-cardiology/articles/2021/01/04/14/ 03/cardiac-rehabilitation-and-implications-during-the-covid-19era. Accessed 1/24/21. This is an expert analysis on CR during COVID times looking at home-based cardiac rehab vs. facility based.

105. Ades PA, Keteyian SJ, Wright JS, Hamm LF, Lui K, Newlin K, et al. Increasing cardiac rehabilitation participation from $20 \%$ to 70\%: a road map from the Million Hearts Cardiac Rehabilitation Collaborative. Mayo Clin Proc. 2017;92(2):234-42. https:// doi.org/10.1016/j.mayocp.2016.10.014. This paper describes a road map that focuses on interventions to reduce $\mathrm{CV}$ deaths with the Million Hearts program and focuses on referral, enrollment and adherence.

106.•• Sikand G, Cole RE, Handu D, deWaal D, Christaldi J, Johnson EQ, et al. Clinical and cost benefits of medical nutrition therapy by registered dietitian nutritionists for management of dyslipidemia: a systematic review and meta-analysis. J Clin Lipidol. 2018;12(5):1113-22. https://doi.org/10.1016/j.jacl. 2018.06.016.. This is a systematic review that identified 34 primary studies with $\mathbf{5 7 0 4}$ subjects who are looking at medical nutrition treatment and find it clinically effective and cost beneficial in patients with dyslipidemia and cardiometabolic risk factors.
107.• O’Connor EA, Evans CV, Rushkin MC, Redmond N, Lin JS. Behavioral counseling to promote a healthy diet and physical activity for cardiovascular disease prevention in adults with cardiovascular risk factors: updated evidence report and systematic review for the US Preventive Services Task Force. JAMA. 2020;324(20):2076-94. https://doi.org/10.1001/jama.2020. 17108 . . This is a review of data to look at medium- and highcontact multisession behavioral counseling interventions which were effective in reducing cardiovascular events, blood pressure, low-density lipoproteins, and adiposity-related outcomes, with little to no risk of serious harm.

108.• Woo BFY, Lee JXY, Tam WWS. The impact of the advanced practice nursing role on quality of care, clinical outcomes, patient satisfaction, and cost in the emergency and critical care settings: a systematic review. Hum Resour Health. 2017;15(1):63. https://doi.org/10.1186/s12960-017-0237-9. Systematic review of impact of nursing on quality of care, clinical outcomes, patient satisfaction, and cost in emergency and critical care settings.

109. Olatunji BO, Kauffman BY, Meltzer S, Davis ML, Smits JA, Powers MB. Cognitive-behavioral therapy for hypochondriasis/health anxiety: a meta-analysis of treatment outcome and moderators. Behav Res Ther. 2014;58:65-74. https://doi.org/10. 1016/j.brat.2014.05.002.

110. Reavell J, Hopkinson M, Clarkesmith D, Lane DA. Effectiveness of cognitive behavioral therapy for depression and anxiety in patients with cardiovascular disease: a systematic review and meta-analysis. Psychosom Med. 2018;80(8):742-53. https://doi. org/10.1097/PSY.0000000000000626. Systematic review and meta-analysis review of CBT for depression and anxiety in CV patients.

111. Trauer JM, Qian MY, Doyle JS, Rajaratnam SM, Cunnington D. Cognitive behavioral therapy for chronic insomnia: a systematic review and meta-analysis. Ann Intern Med. 2015;163(3):191204. https://doi.org/10.7326/M14-2841.

112. Mikosch P, Hadrawa T, Laubreiter K, Brandl J, Pilz J, Stettner H, et al. Effectiveness of respiratory-sinus-arrhythmia biofeedback on state-anxiety in patients undergoing coronary angiography. J Adv Nurs. 2010;66:1101-10. https://doi.org/10.1111/j.13652648.2010.05277.x.

113.• Lee EKP, Yeung NCY, Xu Z, Zhang D, Yu C-P, Wong SYS. Effect and acceptability of mindfulness-based stress reduction program on patients with elevated blood pressure or hypertension. Hypertension. 2020;76(6):1992-2001. https://doi.org/10. 1161/HYPERTENSIONAHA.120.16160. Meta-analysis of effect of mindfulness based stress reduction on patients with elevated blood pressure or hypertension.

114. Reiss-Brennan B, Brunisholz KD, Dredge C, Briot P, Grazier K, Wilcox A, et al. Association of integrated team-based care with health care quality, utilization, and cost. JAMA. 2016;316(8):826-34. https://doi.org/10.1001/jama.2016.11232.

Publisher's Note Springer Nature remains neutral with regard to jurisdictional claims in published maps and institutional affiliations. 


\section{Authors and Affiliations}

Abha Khandelwal ${ }^{1} \cdot$ May Bakir $^{2} \cdot$ Meghan Bezaire $^{3}$ - Briana Costello ${ }^{4}$ Joanne Michelle D. Gomez ${ }^{5} \cdot$ Valerie Hoover $^{6}$. Noreen T. Nazir ${ }^{7} \cdot$ Katherine Nichols $^{8} \cdot$ Amy Reisenberg $^{9} \cdot$ Anupama Rao $^{10} \cdot$ Rupa Sanghani $^{3} \cdot$ Melissa Tracy $^{3}$. Annabelle Santos Volgman ${ }^{3,11}$ (D)

Abha Khandelwal

akhandel@stanford.edu

May Bakir

may.bakir@lumc.edu

Meghan Bezaire

megg_20@hotmail.com

Briana Costello

Bcostello@texasheart.org

Joanne Michelle D. Gomez

Joanne.Gomez@cshs.org

Valerie Hoover

vhoover@stanford.edu

Noreen T. Nazir

nnazir@uic.edu

Katherine Nichols

Knichols6@mgh.Harvard.edu

Amy Reisenberg

AReisenberg@StanfordHealthcare.org

Anupama Rao

Anupama_K_Rao@rush.edu

Rupa Sanghani

Rupa_Sanghani@rush.edu

Melissa Tracy

Melissa_Tracy@rush.edu
1 Division of Cardiology, Women's Heart Health, Stanford University, Palo Alto, CA, USA

2 Division of Cardiology, Women's Heart Health Center, Loyola University, Chicago, IL, USA

3 Rush Heart Center for Women, Division of Cardiology, Rush University Medical Center, Chicago, IL, USA

4 Center for Women's Heart \& Vascular Health, Texas Heart Institute, and Baylor St. Luke's Medical Center Hospital, Houston, TX, USA

5 Barbra Streisand Women's Heart Center, Cedars-Sinai Medical Center, Los Angeles, CA, USA

6 Department of Psychology, Stanford University, Palo Alto, CA, USA

7 Division of Cardiology, Department of Medicine, University of Illinois, Chicago, Chicago, USA

8 Division of Cardiology, Massachusetts General Hospital, Harvard University, Boston, MA, USA

9 Stanford Healthcare, Stanford University, Palo Alto, CA, USA

10 Division of Cardiology, Rush University Medical Center, Chicago, IL, USA

11 Chicago, USA 